\title{
Artemisia species in vitro cultures for production of biologically active secondary metabolites
}

\author{
Marta Grech-Baran *, Agnieszka Pietrosiuk \\ Faculty of Pharmacy, Medical University of Warsaw, Warsaw, Poland \\ *Corresponding author: mgrech@wum.edu.pl
}

\begin{abstract}
An overview of recent studies conducted with the use of various plant tissues, organ culture and plant regeneration of Artemisia species is presented in this paper. Species that belong to this genus contain important secondary metabolites of diverse structure and biological activity. Owing to their valuable pharmacological properties, Artemisia species have been the object of various biotechnological studies. Different in vitromethods of Artemisia $s p$. culture are key to the production of these valuable compounds - especially sesquiterpene lactones - artemisinin and arglabin - used as natural drugs.
\end{abstract}

Key words: Artemisia, cultures in vitro, hairy roots, cultures in bioreactors, artemisinin, arglabin

\section{Introduction}

Over the last years, there have been a number of synthetic drugs used in modern medicine, but the necessity to find novel substances in face of a large number of diseases made space for the exploration of another kind of medical substances - natural drugs, of which plant secondary metabolites constitute the greatest part. These molecules are known for their major role in the adaptation of plants to their environment. At the same time, they represent an important source of active pharmaceuticals. Different strategies, using in vitro systems, have been extensively studied with the objective of improving the production of secondary plant compounds. Compounds received from plants or from in vitro cell and tissue cultures may be directly used as drugs, without any changes, or such compounds may undergo further semisynthetic modifications (Stafford et al., 1986, Bourgaud et al., 2001).

Genus Artemisia belongs to the botanical family of Asteraceae which contains about 23000 species. Most studies have concentrated on such species as: Artemisia absinthium L., Artemisia pontica L., Artemisia judaica L., Artemisia vulgaris L., Artemisia dubia Wall. ex Bess., Artemisia scoparia Waldst. and Kit., and Artemisia annua L. (Adekenov et al., 1982; Liu et al., 2003; 2004; Sujatha et al., 2007; Grech-Baran et Pietrosiuk, 2010).

Members of the Asteraceae family produce a large number of various secondary metabolites that show bio- logical activity. Among them, sesquiterpene lactones and flavonoids are the most interesting ones from the pharmacological point of view. These substances are known for their reported medical efficacy e.g. strong anti-inflammatory, antimalarial, antioxidant, antitumor activity, as well as for the fact that they increase immunity and decrease the risk of atherosclerosis, arthritis and gastrointestinal disorders (Liu et al., 2004; Stojanowska, 2010; Kazemi et al., 2011). In many cases, the $\alpha$-methylene group in the lactone ring of sesquiterpene lactones, being potentially able to bind the nucleophilic sites of biomolecules by conjugate addition, manifests their biological activity (Seitz et Reiser, 2005).

Two most important sesquiterpene lactones used as drugs: artemisinin and arglabin are of natural origin. Artemisinin is an antiparasitic drug isolated from fieldgrown Artemisia annua. It shows a certain activity against chloroquinine-resistant and chloroquinine-sensitive strains of Plasmodium falciparum and is useful in cerebral malaria treatment (Klayman, 1985; Luo et Shen, 1987). The biological production of artemisinin for malarial therapy was largely discussed by Zhao et Liu (2007). In 2012, Crespo-Ortiz et Wei reported that artemisinin and its analogs, which are naturally occurring antimalarials, show a potent anticancer activity. In primary cancer cultures and cell lines, their antitumor actions consists of an inhibiting cancer proliferation, metastasis and angiogenesis. The content of artemisinin 
and its active derivatives in the wild $A$. annua plants is limited, ranging from 0.01 to $0.5 \%$ of dry weight (DW), which makes their acquisition expensive. Additionally, artemisinin as a complex molecule can be chemically synthesized, however, it is not economically attractive (Zeng et al., 2012). The tissue culture of $A$. annua is largely focused on improving artemisinin production. In vitro cultures of this species have been the object of great amount of research (Gulati et al., 1996; Mathur et Kumar, 1996; Nin et al., 1996; Honda et al., 2001; Liu et al., 1997; 1998; 1998a; 2003; 2003a; 2003b; 2004; Sujatha et al., 2007a; Mannan et al., 2010).

Arglabin as a medicine exhibits a strong antitumor activity (Shaikenov et al., 2001; Zhangabylov et al., 2004; Grech-Baran et Pietrosiuk, 2010). This compound was found in two species from Artemisiagenus: A. myriantha Wall. ex Bess. and A. glabella Kar. and Kir. (Adekenov et al., 1993; Bottex-Gauthier et al., 1993; Shaikenov et al., 2001; Wong et Brown, 2002). Kinetic studies showed that the phosphorylated form of Arglabin-DMA (a water-soluble form of arglabin) competitively inhibited the binding of farnesyl diphosphate to farnesyltransfrase (FTase) (End, 1999; Shaikenov et al., 2001). A modification of the arglabin chemical structure increases its major activity and extends its function for the antifungal activity (Dzhalmakhanbetova et al., 2005; Jalmakhabetova et al., 2006; Jalmakhabetova et al., 2007). The immunomodulating properties of arglabin were investigated in vitro. Arglabin-stimulated macrophages displayed a strong cytotoxic activity and induced a significant stimulation of the cell mitochondrial metabolism (BottexGauthier et al., 1993). Unfortunately, there is not much information about in vitro cultures of $A$. glabella or A. myriantha in the studies related to arglabin.

Recently, Krebs et al. (2010) have reported suppression of the tumor necrosis factor alpha (TNF- $\alpha$ ) and other interleukins by $A$. absinthium extracts in in vitro studies. The aim of the study was to establish whether this effect could also be observed in Crohn's Disease (CD) patients. The authors showed that this traditional herb, due to the absence of side effects when administered at recommended amounts, may also prove to be a better alternative to thalidomide, currently enjoying its come back as a backup in TNF- $\alpha$ targeted diseases.

It is widely known that plants from a natural resource or plants propagated by conventional means generally produce small quantities of secondary metabolites which makes their price very high; hence the studies on plant tissues and plant micropropagation offer various advantages for obtaining massive amounts of plant material. The plant micropropagation is an efficient method for propagating disease-free and genetically uniform plants. It also appears that both liquid and solid shoot cultures are a good choice for micropropagation in laboratories because they reduce costs related to the automation of the procedure (Honda et al., 2001).

The artemisinin production in shoot cultures of such species as $A$. pontica, $A$. judaica, $A$. vulgaris, $A$. annua, and $A$. scoparia was investigated by a number of researchers (Gulati et al., 1996; Liu et al., 2003; 2003a; 2004; Mannan et al., 2010; Mathur and Kumar, 1996; Singh and Sarin, 2010; Sujatha et al., 2007).

For mass propagation, bioreactor technologies are also taken into account. In particular, $A$. annua, $A$. indica and $A$. dubia root cultures have been tested in bioreactors as a source of artemisinin (Cai et al., 1995; Kim et al., 2001; 2002; Mannan et al., 2008; Liu et al., 1997; 1998; 1999; 2003b). Emphasis was put on designing appropriate bioreactors suitable to culture delicate and sensitive plant hairy roots.

The root cultures carried out in bioreactors in optimized environmental conditions produce secondary metabolites at levels compared to whole plants (Liu et al., 1998). Abnormal changes in physiology or morphology are also rarer in this environment, because the level of stress caused by environmental conditions is lower than in typical liquid cultures in flasks (Liu et al., 2004).

The aim of this paper was to present an overview of recent studies on Artemisia species carried out with the objective of enhancing sesquiterpene lactone production, by harnessing biotechnological techniques, including the in vitro tissue culture, genetic engineering and bioreactor technology.

\section{Plant regeneration, shoot and callus culture of Artemisia sp.}

In vitro regeneration of plants is an advantageous system because wild grown plants usually develop fungal or bacterial infections. Moreover, environmental factors such as pollution affect some somatic variations. Regeneration in vitro from existing meristems, and via the inflorescence culturing of etiolated hypocotyls as well as seedling micropropagation have been reported for medicinal and aromatic plants, including Artemisia species. 
Shoot tips may be useful for clonal propagation of genetically stable plants with the same path of synthesis on secondary metabolites (Gulati et al., 1996; Mathur et Kumar, 1996; Liu et al., 2003).

In order to enhance biomass yield and artemisinin production, standardization of media composition for the in vitro cultures of Artemisia spp has been extensively investigated (Aslam et al., 2006, Nin et al., 1996, Liu et al., 2003, Liu et al., 2004). The presence of the most active cytokinin like TDZ (N-phenyl-N'-(1,2,3-thidiazol5 -yl)-urea has been found to increase the number of adventitious shoots and shoots elongation (Liu et al., 2003, Sujatha et al., 2007). Apart from auxins, other growth regulators like gibberellins have also been used. Supplementation with $\mathrm{GA}_{3}$ was crucial because the most important artemisinin synthesis pathway in Artemisia spp. is correlated with flowering (Gulati et al., 1996). The effect of various phytohormones on micropropagation of Artemisia species is presented in Table 1.

\section{Factors influencing artemisinin production in different cultures of Artemisia sp.}

The functioning of many secondary metabolite pathways is easily altered by external factors such as nutrient levels, stress factors, light and growth regulators. Many of the constituents of plant cell culture media are important determinants of culture growth and accumulation of secondary metabolites (Misava, 1985; Stafford et al., 1986; Ramachandra et Ravishankar, 2002). Numerous factors have been reported to influence the success of an in vitro production of artemisinin.

\section{Effect of sucrose, nitrogen and phosphate}

The exact effects of the available carbon sources in a secondary metabolite production in plants are not well understood. In an $A$. annua shoot culture, the highest artemisinin concentration was achieved when the sucrose concentration increased to $30 \mathrm{~g} / \mathrm{l}$ (Liu et al., 2003a). However, the increase in sucrose above $70 \mathrm{~g} / 1$, improved artemisinin production in hairy root culture of this species (Liu et al., 1997). Thus, the demand for sucrose as a source of carbon depends on the kind of culture. Weathers et al. (2004) suggested that sugars might affect terpenoid metabolism not only as carbon sources, but also as signal molecules. The authors showed that glucose stimulated artemisinin production in transformed root cultures of $A$. annua. The biomass growth in sucro- se was equivalent to its growth in fructose and was significantly better than in glucose.

Nitrogen was usually supplied into the medium as a combination of salts. It was found that the ratio nitrate to ammonia $\left[\mathrm{NO}_{3}{ }^{-} / \mathrm{NH}_{4}{ }^{+}\right]$influenced the artemisinin production. The biomass and artemisinin concentrations for $A$. annua decreased with a higher ammonia to nitrate ratio. The optimum ratio of ammonia to nitrate was 1:3 for the production of artemisinin from $A$. annua in vitro shoot cultures. The increase in phosphate concentration to $200 \mathrm{mg} / \mathrm{l}$ favorably influenced artemisinin production, however concentrations above it led to a significant decrease in shoot cultures (Liu et al., 2003a). Investigations in root culture show that a high ratio of nitrate to ammonia and a low total nitrogen concentration in the medium leads to a high secondary metabolite concentration (Ramachandra et Ravishankar, 2002).

Four factors: phosphate and nitrate salts, sucrose, and culture inoculum age were analyzed simultaneously to determine the most suitable conditions for maximizing both root biomass and sesquiterpene lactones production in transformed $A$. annua root cultures by Weathers et al. (1997). The authors concluded that optimal growth conditions were determined to be: nitrate (15 $\mathrm{mM})$, phosphate $(1.0 \mathrm{mM})$, sucrose content $(5 \% \mathrm{w} / \mathrm{v})$, and inoculum age (8 day-old) whereas the determination of optimal conditions for sesquiterpene production was more complicated and did not provide the most effective solutions for maximizing the production of artemisinin.

\section{Effect of phytohormones and amino acids}

The effect of the five main hormones: IAA, cytokinins, ethylene, gibberellins $\left(\mathrm{GA}_{3}\right)$, and abscisic acid (ABA) and the basic amino acid on the growth and secondary metabolism of $A$. annua hairy roots was researched. Cai et al. (1995) compared the influence of gibberellin and auxin on the growth and artemisinin production in a hairy root culture of $A$. annua. An addition of $0.025 \mathrm{mg} / \mathrm{l}$ of NAA to the medium enhanced the hairy roots growth, but inhibited the artemisinin yield. On the contrary, supplementation of gibberellic acid $(4.8 \mathrm{mg} / \mathrm{l})$ stimulated both factors. Roots of $A$. annua incubated in a B5 medium supplemented with IAA inhibited the production of secondary metabolites more than those grown in synthetic auxins. A high concentration of IAA also stimulated the production of ethylene which inhibited the artemisinin production. IAA, $\mathrm{GA}_{3}, \mathrm{BA}$, and $\mathrm{ABA}$ sig- 
Table 1. The effect of various phytohormones on micropropagation of Artemisia species

\begin{tabular}{|c|c|c|c|c|}
\hline $\begin{array}{l}\text { Artemisia } \\
\quad \text { spp. }\end{array}$ & Medium & Phytohormones & Results & References \\
\hline \multirow{3}{*}{$\begin{array}{l}\text { Artemisia } \\
\text { scoparia }\end{array}$} & \multirow{3}{*}{ MS } & $2,4-\mathrm{D}, \mathrm{NAA}$ & $\begin{array}{l}\text { callus induction from shoot tip }(80-100 \%) \text {, } \\
\text { leaf and petiole explants }(50-100 \%)\end{array}$ & \multirow{3}{*}{$\begin{array}{l}\text { Aslam et al., } \\
2006\end{array}$} \\
\hline & & $\mathrm{NAA}, \mathrm{BA}, \mathrm{KN}$ & shoot proliferation (90\%) & \\
\hline & & NAA & root initiation $(75-87.5 \%)$ & \\
\hline \multirow{3}{*}{$\begin{array}{l}\text { Artemisia } \\
\text { absinthium }\end{array}$} & \multirow{3}{*}{ MS } & $\begin{array}{l}\text { BA, KN, NAA, } \\
\text { IAA, } 2,4-\mathrm{D}\end{array}$ & callus induction from micropropagated plantlets & \multirow{3}{*}{$\begin{array}{l}\text { Nin et al., } \\
\quad 1996\end{array}$} \\
\hline & & $2,4-\mathrm{D}$ & $\begin{array}{l}\text { roots and shoots initiation directly } \\
\text { from shoots explants }\end{array}$ & \\
\hline & & BA, IAA & adventitious shoots initiation from callus & \\
\hline $\begin{array}{l}\text { Artemisia } \\
\text { vulgaris }\end{array}$ & MS & $\mathrm{TDZ}$ & $\begin{array}{l}\text { adventitious shoots formation from hypocotyl } \\
\text { segments ( } 28 \text { shoots per explant) }\end{array}$ & $\begin{array}{l}\text { Sujatha et al., } \\
2007\end{array}$ \\
\hline $\begin{array}{l}\text { Artemisia } \\
\text { vulgaris }\end{array}$ & $\begin{array}{l}\text { MS supplemented } \\
\text { with } B_{5} \text { vitamins }\end{array}$ & $\mathrm{BA}, \mathrm{KN}$ & $\begin{array}{l}\text { shoots formation from shoot tips and nodal } \\
\text { explants ( } 23 \text { shoots per explant) }\end{array}$ & $\begin{array}{l}\text { Sujatha et al., } \\
2007 \mathrm{a}\end{array}$ \\
\hline $\begin{array}{l}\text { Artemisia } \\
\text { judaica }\end{array}$ & $\begin{array}{l}\text { MS supplemented } \\
\text { with } B_{5} \text { vitamins }\end{array}$ & $\mathrm{TDZ}$ & $\begin{array}{l}\text { shoots organogenesis induced by culturing } \\
\text { etiolated hypocotyls and intact seedlings } \\
\text { (16 shoots per seedling) }\end{array}$ & $\begin{array}{l}\text { Liu et al., } \\
\quad 2003\end{array}$ \\
\hline $\begin{array}{l}\text { Artemisia } \\
\text { judaica }\end{array}$ & $\begin{array}{l}\text { MS supplemented } \\
\text { with } B_{5} \text { vitamins }\end{array}$ & IBA & $\begin{array}{l}\text { shoots organogenesis induced by culturing } \\
\text { etiolated hypocotyls and intact seedlings (75\%) }\end{array}$ & $\begin{array}{l}\text { Liu et al., } \\
2004\end{array}$ \\
\hline \multirow[t]{2}{*}{$\begin{array}{l}\text { Artemisia } \\
\text { annua }\end{array}$} & \multirow{2}{*}{$\begin{array}{l}\text { MS supplemented } \\
\text { with RT vitamins } \\
\text { and casein hydrolisate }\end{array}$} & $\mathrm{BA}$ & $\begin{array}{c}\text { conversion of terminal heads of inflorescence } \\
\text { leads to leafy structures with subsequent } \\
\text { elongation of axillary shoots }\end{array}$ & \multirow{2}{*}{$\begin{array}{l}\text { Mathur } \\
\text { et Kumar, } \\
1996\end{array}$} \\
\hline & & IBA & roots formation from regenerated shoots & \\
\hline $\begin{array}{l}\text { Artemisia } \\
\text { annua }\end{array}$ & $\begin{array}{l}\text { MS supplemented } \\
\text { with aspartic acid, } \\
\text { glutamine, arginine, } \\
\text { cysteine hydrochloride }\end{array}$ & $\mathrm{NAA}, \mathrm{GA}_{3}, \mathrm{BA}$ & $\begin{array}{l}\text { shoot regenerated from juvenile or vegetative } \\
\text { parts of mature plant }\end{array}$ & $\begin{array}{l}\text { Gulati et al., } \\
1996\end{array}$ \\
\hline
\end{tabular}

IAA - B-indole-3-acetic acid; BA - benzyladenine; IBA - indole-3-butyric acid; NAA - 1-naphthaleneacetic acid; KN - kinetin; 2,4-D - 2,4dichlorophenoxyacetic acid; TDZ - N-phenyl-N'-(1,2,3-thidiazol-5-yl)urea; GA3 - gibberellic acid; MS - Murashige et Skoog medium (Murashige et Skoog, 1962); $\mathrm{B}_{5}$ - Gamborg medium (Gamborg et al., 1968); RT vitamins (Khanna et Staba, 1968)

nificantly inhibited artemisinin production, when compared to cultures supplemented with NAA. Single roots grown in a $\mathrm{B} 5$ medium with $\mathrm{GA}_{3}(0.029 \mu \mathrm{mol})$ produced the highest values for a number of lateral roots, the length of primary roots, and the lateral root tip density. An addition of 2-isopentenyladenine inhibited the root growth, but stimulated the artemisinin production more than twice in comparison to the controls (Weathers et al., 2005). In shoot cultures of $A$. annua, various $\mathrm{GA}_{3}$ concentrations influenced the growth and production of artemisinin (Liu et al., 2003a).

In order to optimize artemisinin productivity in shoot cultures of $A$. annua, Liu et al., (2003a) examined the influence of nutrient components and hormones. Shoot cultures were established on an MS basal medium which contained $30 \mathrm{~g} / 1$ sucrose, $0.5 \mathrm{mg} / 1 \mathrm{BA}$ and $0.05 \mathrm{mg} / \mathrm{l} \mathrm{NAA}$. Using an optimized combination of sucrose $(30 \mathrm{~g} / \mathrm{l})$, nitrate $(45 \mathrm{mM})$, inorganic phosphate $(200 \mathrm{mg} / \mathrm{l}), \mathrm{GA}_{3}(7 \mathrm{mg} / \mathrm{l})$ and the ratio of nitrate to ammonia (1:3), artemisinin production reached $26.7 \mathrm{mg} / 1$ after 30 days.

The effect of amino acids: valine, cystine and growth regulators: BA, NAA,on the production of artemisinin in callus of $A$. absinthium was also explored. Callus for the research was obtained from leaf explants which contained $223 \mu \mathrm{g}$ of artemisinin per $1 \mathrm{~g}$ of fresh weight (FW). Very 
good results on callus growth and high concentrations of artemisinin were achieved when valine $(12.5 \mathrm{mg} / \mathrm{l})$, or cystine $(12.5 \mathrm{mg} / \mathrm{l})$, and phytohormones: BA $(2 \mathrm{mg} / \mathrm{l})$, NAA $(2 \mathrm{mg} / \mathrm{l})$, were added to the medium. The amount of artemisinin in the callus culture was $3.1 \mu \mathrm{g} / \mathrm{g}$ after supplementation with valine, $2.8 \mu \mathrm{g} / \mathrm{g}$ following the addition of cystine. The amount of artemisinin in the callus cultures was $3.05 \mu \mathrm{g} / \mathrm{g}$ and $1.95 \mu \mathrm{g} / \mathrm{g}$ respectively, when BA $(2 \mathrm{mg} / \mathrm{l})$ and NAA $(2 \mathrm{mg} / \mathrm{l})$ were present in the medium (Zia et al., 2007).

Jing et al. (2009) showed that the artemisinin content in $A$. annua plants treated with $10 \mu \mathrm{M}$ ABA was $65 \%$ higher than that in the control plants, up to an average of $1.84 \%$ dry weight. The authors also suggested that there is a crosstalk between the ABA signaling pathway and the artemisinin biosynthetic pathway, and that CYP71AV1 (amorpha-4,11-diene C-12 oxidase gene), which was induced most significantly, may play a key regulatory role in the artemisinin biosynthetic pathway.

Banyai et al. (2011) observed enhancement of artemisinin content and leaf biomass in $A$. annua by exogenous $\mathrm{GA}_{3}$ treatment. The increased artemisinin content was associated with an increased synthesis of key enzymes in the artemisinin biosynthesis pathway due to the $\mathrm{GA}_{3}$ application. Interestingly, an exogenous $\mathrm{GA}_{3}$ application continuously enhanced the artemisinin content from the vegetative stage to the flower initiation in both plant lines and gave a significantly higher leaf biomass than in the control plants. Consequently, the artemisinin yield in $\mathrm{GA}_{3}$-treated plants was much higher than in the control plants.

Singh and Sarin (2010) concluded that $A$. scoparia is an alternative to $A$. annua for the production of artemisinin. Both aerial parts of the plant and callus culture contained artemisinin in amounts of $0.015 \%$ and $0.001 \%$, respectively. Unorganized callus of $A$. scoparia was raised from the young nodal stem segments on an MS medium supplemented with 2,4-D (3 mg/l), kinetin $(0.25 \mathrm{mg} / \mathrm{l})$ and proline $(100 \mathrm{mg} / \mathrm{l})$.

\section{Effect of light}

Light has a stimulatory, or inhibitory, influence on the secondary metabolite accumulation in tissues. Moreover, it is involved in the regulation of the secretion mechanism for these products. Attempts were made to investigate the influence of light irradiation on the growth accumulation of artemisinin for $A$. annua. Experi- ments showed that thirty days with 16 hours light exposition (3000 Lux, cool white fluorescent lamps) followed by an 8-hour-darkness, resulted in the highest levels of artemisinin for hairy roots culture $(244.5 \mathrm{mg} / \mathrm{l})$. Tests with darkness or continuous light conditions did not bring such good results (Liu et al., 2002).

\section{Addition of precursors or elicitors}

Sodium acetate, mevalonic acid lactone and casein acid hydrolysate were used to increase artemisinin production in a suspension culture of $A$. annua. The first one could be useful because of increasing acetyl-CoA, the second one is the nearest intermediate of isoprene units, while the third one obviously increases the sesquiterpene content due to the supply of additional amino acids. Using abiotic elicitors like: methyl jasmonate or biotic: chitosan, significantly improves the production of artemisinin and indicates the potential of biotechnologybased methodologies for a large-scale production of artemisinin (Baldi et Dixit, 2008).

Another way of stimulating the production of artemisinin was to feed the rooted shoots of $A$. annua cultured in vitro with dimethyl sulfoxide (DMSO) at different concentrations $(0.25$ and $2.0 \%)$. This procedure allows to increase twofold the level of artemisinin and its precursor - dihydroartemisinic acid. What is more, DMSO affects some of the genes in the artemisinin biosynthetic pathway (Mannan et al., 2010).

\section{Transformed root cultures}

The roots of higher plants display remarkably diverse secondary metabolites. The genetic transformation of plants with the use of a natural vector system Agrobacterium rhizogenes is the most often applied technique of DNA insertion into the genome of a plant. Other transformation techniques are chemical methods, electroporation, microinjection or bombardment. The neoplastic roots produced by $A$. rhizogenes infection are characterized by a high growth rate and genetic stability. Roots grow rapidly and produce secondary metabolites at higher levels compared to those in mother plants. (Giri et Lakshmi Narasu, 2000; Wasilewska et Królicka, 2005). "Hairy root" or "transformed root" systems have been known for more than three decades. To date, hairy root cultures have been obtained from more than 100 plant species, including several endangered medicinal plants, affording opportunities to produce important 
phytochemicals and proteins in eco-friendly conditions (Georgiev et al., 2007).

Xie et al. (2001) concluded that hairy roots of $A$. annua could be induced from different kinds of explants. Tests proved that the efficiency of leaf blade pieces forming roots was higher than that of petiole segments. Light promoted hairy root induction and branching. Shoot tip cultures of $A$. annua were also infected with $A$. rhizogenes. A hairy root induction could be observed after 2-3 weeks on $1 / 2$ MS basal medium containing 1\% sucrose (Vishweshwar Rao et al., 1998). Moreover, the transgenic state of transformed roots and the expression of gene could be confirmed by Southern blot hybridization and an enzymatic assay (Mannan et al., 2008).

The influence of physical and chemical factors on the growth of transformed roots was also studied. For A. dubia, $A$. indica and $A$. annua, the searched secondary metabolite was artemisinin, which could be detected in a hairy root culture only under 16 hours photo-period condition (Cai et al., 1995; Mannan et al., 2008). A further effect of these factors on the hairy root culture included a low concentration of NAA $(0.025 \mathrm{mg} / \mathrm{l})$ which enhanced the growth of the roots, but inhibited the production of artemisinin. Artemisinin production in those cultures was higher after the addition of gibberellin to the medium (Mannan et al., 2008).

A scaled-up hairy root culture of $A$. annua was established by Xie et al. (2000). Two compounds: artemisinin and stigmasterol derived from the common precursors of isopentenyl diphosphate and farnesyl pyrophosphate were isolated from hairy roots. The production rate of artemisinin from hairy root cultures was $0.54 \%$ (mg/g DW).

Hairy roots obtained by Ri-mediated transformation of $A$. annua with a recombinant farnesyl diphosphate synthase gene produced 2-3 $\mathrm{mg}$ of artemisinin per $1 \mathrm{~g}$ of tissue dry weight (DW). It was about 3-4 times higher than that in the control hairy roots. Also, these roots grew faster than the control hairy roots (Chen et al., 1999). Moreover, Chen et al. (2000) developed an Agrobacterium tumefaciens - mediated transformation system for Artemisia annua L. Using that system, a cDNA encoding farnesyl diphosphate synthase (FDS placed under a $\mathrm{CaMV} 35 \mathrm{~S}$ promoter) was transferred into $A$. annua via $A$. tumefaciens strain LB4404. The transgenic plants produced a 2-3 times higher artemisinin $(8-10 \mathrm{mg} / \mathrm{g} \mathrm{DW})$ than the control plants.

\section{Cultures in bioreactors}

Various bioreactor configurations have been used to cultivate hairy roots and shoot cultures of Artemisia species. The reactors could be classified as either a liquid phase or a gas phase. The liquid phase consists of conventional fermentors and bubble column reactors. Roots in those types of reactors are immersed in the medium (Kim et al., 2001).

In the gas phase reactors, the roots are strongly exposed to the mixture of gases. Nutrient mist bioreactors and trickle-bed bioreactors occur in this group. Tricklebed bioreactors with a countercurrent flow of gas and liquid are used on a large scale as biofilters for the gas cleanups, deodorization and water purification. For Artemisia cultures, mist bioreactors are widely used. There are a lot of types of mist bioreactors e.g. the nutrient mist bioreactor (NMB) and its modifications: the inner loop nutrient mist bioreactor (INMB), the modified inner loop nutrient mist bioreactor (MINMB). The research showed that the growth yield of hairy roots $A$. annua cultivated in those three types of bioreactors was uniform on each mesh after 15 days cultivation. However, the growth in NMB and INMB became nonuniform after 25 days. During that time, the growth index (final dry weight/ initial dry weight) of the roots was the highest in MINMB - 68, the smallest in NMB - 42 . The index for INMB was 61 (Liu et al., 1999).

Other data for the MINMB showed that under the optimum misting cycle ( 3 min of nutrient mist and next 90 min of intermission) the artemisinin content significantly increased and reached $46.9 \mathrm{mg} / \mathrm{l}$, after 25 days of cultivation. Another possibility for $A$. annua hairy root cultivation is a modified inner loop airlift bioreactor (MILAB). The research showed that the optimum conditions for a higher production of metabolites in $A$. annua hairy root cultures in MILAB are as follows: $\mathrm{pH} 5.5$ \pm 6.0 , air flow rate $3.0 \mathrm{dm}^{3} / \mathrm{min}$, cycle of light irradiation $16 \mathrm{~h} / \mathrm{d}$ and temperature $28^{\circ} \mathrm{C}$ (Liu et al., 1998).

Comparing the MILAB with the classic, as well as the modified bubble reactors, attested that growth rate, and hairy root distribution in the MILAB were better than those in bubble reactors. The dry weight and artemisinin production reached $26.8 \mathrm{~g} / \mathrm{l}$ and $536 \mathrm{mg} / \mathrm{l}$ after twenty days of culture (Wang et al., 1998). Moreover, the nutrient mist bioreactor could be used not only for culturing transformed roots, but also for the micropropagation process. The acoustic window mist bioreactor 
is an example of devices useful for both procedures. The transformed roots of $A$. annua clone YUT16 were used in this experiment (Chatterjee et al., 1997). For the achievement of the maximum artemisinin production, an ultrasonic mist bioreactor (UNMB) and a modified ultrasonic mist bioreactor (MUNMB) were tested. Although the shoots cultivated in both reactors showed an excellent growth, the best results were obtained in the MUNMB. The dry weight increased 35 times, and the component of artemisinin increased 2.0-fold (SharafEldin et Ekholy, 2009).

Although in each of the bioreactors the cultures grew well, in the MILAB the results of hyperhydration and stress were observed. Comparing the studies of bioreactors, the MILAB is not suited for a shoot culture. The growth of shoots was the best in the mist bioreactor because the liquid nutrient delivered efficiently to each part of the shoot cultures, In addition, in the nutrient mist bioreactor, the level of artemisinin was the highest (Kim et al., 2001). The comparative study of the nutrient mist and bubble column reactors showed that roots which grew in the mist reactor, had a higher secondary metabolite content than those grown in the bubble column reactor. The results showed that hairy roots of $A$. annua grown in the mist reactors produced three times as much of artemisinin per gram dry weight as the roots grown in the bubble column reactors. The main difference between the mist and the bubble column reactors was the provision of a circulation system and hydrodynamic behavior (Liu et al., 2003b).

Modifications of the bubble reactor consisted of two additional meshes. Hairy root cultures between the meshes were progressively attached to each mesh. This modification made the root growth homogeneous, but it was still insufficiently effective. On the other hand, the bubble column reactor accumulated more biomass than the mist reactors. These results suggest that the lower growth rates in the mist bioreactors may be due to the insufficient nutrient availability (Kim et al., 2002; Towler et Weathers, 2004).

Oxygen is another factor that also influences artemisinin production. In an oxygen-limited bioreactor or shake flasks, the roots grow very poorly. In a mist bioreactor, oxygen is not limited. Moreover, it provides an increase in nutrient absorption by a plant tissue in comparison to an oxygen-limited reactor (Towler et Weathers, 2004).

\section{Conclusions}

The mini review of the biotechnological methods presented in this paper focused on studies aimed at improving artemisinin and arglabin production in Artemisia sp. The yield of artemisinin in field grown plants is relatively low ( 0.01 to $0.5 \%$ of $\mathrm{DW})$. The total organic synthesis is very complicated and economically unattractive. Therefore, an enhanced production of artemisinin either in cell/tissue culture or in the whole plant of Artemisia sp. is highly desirable.

This paper demonstrates that it is mainly the shoot cultures and the mist reactor hairy root cultures of Artemisia genus that could be a source of a highly efficient biological material. The content of artemisinin in $A$. annua plants cultured in vitro was $65 \%$ higher than in the control plants. Additionally, $A$. scoparia could be an alternative to $A$. annua for the production of artemisinin $(0.015 \%$ and $0.001 \%$ of DW in aerial parts of plants and callus, respectively). Also, the callus tissue of $A$. absinthium growing in the medium supplemented with amino acids and phytohormones could be a promising source for the production of artemisinin.

Agrobacterium rhizogenes transformation for Artemisia species has been widely used. The hairy roots of A. annua obtained by Ri-mediated transformation system with a recombinant farnesyl diphosphate synthase gene produced artemisinin that was about 3-4 times higher than the control hairy roots $(2-3 \mathrm{mg} / \mathrm{g} \mathrm{DW})$. Also an Agrobacterium tumefaciens-mediated transformation system for $A$. annua has been developed. Transgenic plants obtained in this way produced 2-3 times higher artemisinin $(8-10 \mathrm{mg} / \mathrm{g} \mathrm{DW})$ than the control plants.

Various bioreactor configurations have been used to cultivate hairy roots and shoot cultures of Artemisia species. After the review of the used bioreactors, we concluded that a mist bioreactor, especially an inner-loop nutrient mist bioreactor (INMB), or a modified inner loop mist bioreactor (MINB), have good results for cultures of this species. Dry weight and artemisinin production of $A$. annua hairy roots reached $26.8 \mathrm{~g} / 1$ and $536 \mathrm{mg} / \mathrm{l}$ after twenty days of culture.

Arglabin, an important plant-derived drug, is still acquired commercially from plants cultivated by conventional means such as cuttings and seeds. Therefore the optimization of $A$. glabella and A. myriantha micropropagation could be very useful. The plant biotechnology strategies, as well as a plant-cell culture technology, 
could give an abundant and a promising future for plantderived active compounds for use in medicine. They may also be of help in the conservation and sustainable use of the species. A better understanding of the biosynthetic pathways of plant secondary metabolites leads to an increase in its biosynthesis by the regulation of both exogenous and endogenous factors.

\section{References}

Adekenov S.M., Mukhametzhanov M.N., Kagarlitskii A.D., Kupriyanov A.N. (1982) Arglabin - A new sesquiterpene lactone from Artemisia glabella. Chem. Nat. Compd. 18(5): 623-624.

Adekenov S.M., Turdybekov K.M., Aituganoav K.A., Lindeman

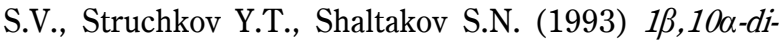
hydroxyarglabin - a new sesquiterpene lactone from Artemisia glabella. Chem. Nat. Compd. 29(6): 735-739.

Aslam N., Zia M., Chaudchary M.F. (2006) Callogenesis and direct organogenesis of Artemisia scoparia. Pak. J. Biol. Sci. 9: 1783-1786.

Baldi A., Dixit V.K. (2008) Yield enhancement strategies for artemisinin production by suspension cultures of Artemisia annua L. Bioresour. Technol. 99: 4609-4614.

Banyai W., Mii M., Supaibulwatana K. (2011) Enhancement of artemisinin content and biomass in Artemisia annua by exogenous $\mathrm{GA}_{3}$ treatment. Plant Growth Regul 63: 45-54.

Bottex-Gauthier C., Vidal D., Picot F., Potier P., Menichini F., Appendino G. (1993) In vitro biological activities of arglabin a sesquiterpene lactone from the Chinese herb Artemisia myriantha Wall. Biotechnol. Ther. 4(1-2): 77-98.

Bourgaud F., Gravot A., Milesi S., Gontier E. (2001) Production of plant secondary metabolites: a historical perspective. Plant Sci. 161: 839-851.

Cai G., Li G.,Ye H., Li G. (1995) Hairy root culture of Artemisia annua $L$. by Ri plasmid transformation and biosynthesis of artemisinin. Chin. J. Biotechnol. 11: 4 227-235.

Chatterjee C., Correll M.J., Weathers P.J., Wyslouzil B.E. (1997) Simplified acoustic window mist bioreactor. Biotechnol. Tech. 11: 155-158.

Chen D.H., Liu C.J., Ye H.C., Li G.F., Liu B.Y., Meng Y.L., Chen X.Y. (1999) Ri-mediated transformation of Artemisia annua with a recombinant farnesyl diphosphate synthase gene for artemisinin production. Plant Cell Tissue Organ. Cult. 57: 157-162.

Chen D.H., Ye H.C., Li G.F. (2000) Expression of a chimeric farnesyl diphosphate synthase gene in Artemisia annua L. transgenic plants via Agrobacterium tumefaciens-mediated transformation. Plant Sci. 155(2): 179-185.

Crespo-Ortiz M.P., Wei M.Q. (2012) Antitumor activity of Artemisinin and its derivatives: from a well-known antimalarial agent to a potential anticancer. Drug. J. Biomed. Biotechnol. 2012: 1-18.

Dzhalmakhanbetova R.I., Adekenov S.M., Atazhanova G.A. (2005) 1,10b-epoxy-3,4-dibromo-11,13b-dibromomethano-
5a,7a,6b(H)-guai-12-olide possessing high antifungal activity. Rep. Kaz. Pat. No. 2005/0290.1.

End D.W. (1999) Farnesyl protein transferase inhibitors and other therapies targeting the Ras signal transduction pathway. Invest. New Drugs. 17: 241-258.

Gamborg O.L., Miller R., Ojima K. (1968) Nutrient requirements of suspension cultures of soybean root cells. Exp. Cell Res. 50: 151-158.

Georgiev M.I., Pavlov A.I., Bley T. (2007) Hairy root type plant in vitro systems as sources of bioactive substances. Appl. Microbiol. Biotech. 74(6): 1175-1185.

Giri A., Lakshmi Narasu M. (2000) Transgenic hairy roots: recent trends and applications. Biotechnol. Adv. 18: 1-22.

Grech-Baran M., Pietrosiuk A. (2010) Arglabin - sesquiterpene lactone revealing antitumor activity. Bull. Faculty Pharmacy Med. Univ. Warsaw 3: 22-26.

Gulati A., Bharel S., Jain S.K., Abdin M.Z., Srivastawa P.S. (1996) In vitro micropropagation and flowering in Artemisia annua. J. Plant Biochem. Biotechnol. 5: 31-35.

Honda H., Liu C.Z, Kobayashi T. (2001) Large-scale plant micropropagation. Adv. Biochem. Eng. Biotechnol. 72: 157-182.

Jalmakhanbetova R.I., Atazhanova G.A., Raldugin V.A., Bagryanskaya Yu.V., Adekenov S.M. (2007) Preparation and structure elucidation of two minor products from reaction of arglabin with chloroform in the presence of a crown ether. Chem. Nat. Compd. 43(5): 548-551.

Jalmakhanbetova R.I., Atazhanova G.A., Raldugin V.A., Bagryanskaya Y.V., Gatilov M., Adekenov S.M. (2006) Crystal structure of a tetrabromine derivative of cyclopropyldihydroarglabin and its antifungal activity. Chem. Nat. Compd. 42(3): 307-309.

Jing F., Zhang L., Li M., Tang Y., Wang Y., Wang Y., Wang Q., Pan Q., Wang G., Tang K. (2009) Abscisic acid (ABA) treatment increases artemisinin content in Artemisia annua by enhancing the expression of genes in artemisinin biosynthetic pathway. Biologia 64(2): 319-323.

Kazemi M., Dakhili M., Dadkhah A., Yasrebifar Z., Larijani K. (2011) Composition, antimicrobial and antioxidant activities of the essential oil of Artemisia kermanensis Podl., an endemic species from Iran. L. J. Med. Plant. Res. 5(18): 4481-4486

Khanna P., Staba J.E. (1968) Antimicrobials from plant tissue cultures. Lloydia 31(2): 180-189.

Kim Y., Wyslouzil B.E., Weathers P.J. (2001) A comparative study of mist and bubble column reactors in the in vitro production of artemisinin. Plant Cell Rep. 20: 451-455.

Kim Y.J., Weathers P.J., Wyslouzil B.E. (2002) Growth of Artemisia annua hairy roots in liquid - and gas-phase reactors. Biotechnol. Bioeng. 80(4): 454-464.

Klayman D.L. (1985) Qinghaosu (artemisinin): an antimalarial drug from China. Science. 228: 1049-1055.

Krebs S., Omer T.N., Omer B. (2010) Wormwood (Artemisia absinthium) suppresses tumor necrosis factor alpha and accelerates healing in patients with Crohn's disease A controlled clinical trial. Phytomedicine 17: 305-309.

Liu C., Wang Y., Guo C., Ouyang F., Ye H.C., Li G.F. (1998) Enhanced production of artemisinin by Artemisia annua 
$L$ hairy root cultures in a modified inner-loop airlift bioreactor. Bioprocess. Eng. 19: 389-392.

Liu C.Z, Guo C., Wang Y., Ouyang F. (2002) Effect of light irradiation on hairy root growth and artemisinin biosynthesis of Artemisia annua L. Procces Biochem. 38: 581-585.

Liu C.Z, Wang Y., Ouyang F., Ye H.C., Li G.F. (1997) Production of artemisinin by hairy root cultures of Artemisia annua L. Biotechnol. Lett. 19: 927-930.

Liu C.Z., Guo C., Wang Y, Ouyang F. (2003a) Factors influencing artemisinin production from shoot cultures of Artemisia annua L. World J. Microbiol. Biotechnol. 19: 535-538.

Liu C.Z., Murch S.J., El-Demerdash M. (2003) Regeneration of Egyptian medicinal plant Artemisia judaica L. Plant Cell Rep. 21(6): 525-530.

Liu C.Z., Murch S.J., El-Demerdash M., Saxena P.K. (2004) Artemisia judaica L. micropropagation and antioxidant activity. J. Biotech. 110: 63-71.

Liu C.Z., Wang Y.B., Ouyang F., Ye H.C., Guo C. (2003b). Comparison of various bioreactor on growth and artemisinin biosynthesis on Artemisia annua L. shoot cultures. Proc. Biochem. 39: 45-49.

Liu C.Z., Wang Y.C., Guo C., Ouyang F., Ye H.C., Li G.F. (1998a) Production of artemisinin by shoot cultures of Artemisia annua $L$. in a modified inner-loop mist bioreactor. Plant Sci. 135: 211-217.

Liu C.Z., Wang Y.C., Zahao B., Ouyang F., Ye H.C., Li G.F. (1999) Development of a nutrient mist bioreactor for growth of hairy roots. In vitro Cell Dev. Biol.-Plant. 35: 271-274.

Luo X.D., Shen, C.C. (1987) The chemistry, pharmacology and clinical applications of Qinghaosu (artemisinin) and its derivatives. Med. Res. Rev. 7: 29-52.

Mannan A., Liu C., Arsenault P.R., Towler M., Vail D., Lorence A., Weathers P. (2010) DMSO triggers the generation of ROS leading to an increase in artemisinin and dihydroartemisinic acid in Artemisia annua shoot cultures. Plant Cell Rep. 29: 143-145.

Mannan A., Shaheen N., Arshad W., Qureshi R.A., Zia M., Mirza B. (2008) Hairy roots induction and artemisinin analysis in Artemisia dubia and Artemisia indica. Afr. J. Biotechnol. 18: 3288-3292.

Mathur A.K., Kumar S. (1996) Micropropagation of Artemisia annua via the inflorescence. J. Herbs Sp. Med. Plants. 4: 61-71.

Misava M. (1985) Production of useful plant metabolites. In: Flechter A., editors. Adv. Biochem. Eng. Biotechnol. Springer-Verlag, Berlin: 59-88.

Murashige T., Skoog F. (1962) A revised medium for rapid growth and bioassays with tobacco tissue cultures. Physiol. Plant. 15: 473-497.

Nin S., Mosori E., Schiff S., Bennici A. (1996) Callus cultures of Artemisia absinthium L. Initiation, growth optimization and organogenesis. Plant Cell Tissue Organ Cult. 45: 67-72.

Ramachandra Rao S., Ravishankar G.A. (2002) Plant cell cultures: Chemical factories of secondary metabolites. Biotechnol. Adv. 20: 101-153.
Seitz M., Reiser O. (2005) Synthetic approaches towards structurally diverse $\gamma$-butyrolactone natural product-like compounds. Curr. Opin. Chem. Biol. 9: 285-292.

Shaikenov T.E., Adekenov S.M., Williams R.M., Prashad N., Baker F.L., Madden T.L., Newman R. (2001) Arglabin$D M A$, a plant derived sesquiterpene, inhibits farnesyltransferase. Oncol. Rep. 8(1):1 73-179.

Sharaf-Eldin M., Elkholy S. (2009) Artemisinin production from different shoot culture systems of Artemisia annua L. Aust. J. Basic Appl. Sci. 3(3): 2212-2216.

Singh A., Sarin R. (2010) Artemisia scoparia - A new source of artemisinin. Bangladesh J. Pharmacol. 5(1): 17-20.

Stafford A., Morris P., Fowler M.W. (1986) Plant cell biotechnology: a perspective. Enzyme Microb. Technol. 8: 19-23.

Stojanowska A. (2010) In vitro cultures of some plants from the Asteraceae family as a source of bioactive molecules. International Conference of Perspectives Cytostatic Compounds Production Using Biotechnological Methods, Warsaw 13 April 2010: 152.

Sujatha G., Rajnitha Kumari B.D. (2007) High-Frequency shoot multiplication in Artemisia vulgaris L. using thidiazuron. Plant Biotechnol. Rep. 1: 149-154.

Sujatha G., Rajnitha Kumari B.D. (2007a) Effect of phytohormones on micropropagation of Artemisia vulgaris $L$. Acta Physiol. Plant. 29: 189-195.

Towler M.J., Weathers P.J., (2004) Effects of a nutrient mist bioreactor system on growth kinetics and secondary metabolism of transformed roots of Artemisia annua. $\mathrm{AlChE}$ Ann. Meeting Conf. Proc. 8685-8688.

Vishweshwar Rao K., Venkanna K.V, Narsau M.L. (1998) Agrobacterium rhizogenes mediated transformation of Artemisia annua. J. Sci. Ind. Res. 57 (10-11): 773-776.

Wang C.Z., Ouyang F, Ye H.C., Li G.F. (1998) Production of artemisinin by hairy cultures of Artemisia annua L. in bioreactor. Biotechnol. Lett. 20 (3): 265-268.

Wasilewska A., Królicka A. (2005) Formation and characterization of hairy roots. Biotechnologia 4(71): 173-188.

Weathers P.J., Bunk G., McCoy M.C. (2005) The effect of phytohormones on growth and artemisinin production in Artemisia annua L. hairy roots. In vitro Cell Dev. Biol.Plant. 41: 47-53.

Weathers P.J., DeJesus-Gonzalez L., Kim Y.J., Souret F.F., Towler M.J. (2004) Alteration of biomass and artemisinin production in Artemisia annua hairy roots by media sterilization method and sugars. Plant Cell Rep. 23: 414-418.

Weathers P.J., Hemmavanh D.D., Walcerz D.B., Cheetham R.D., Smith T.C. (1997) Interactive effects of nitrate and phosphate salts, sucrose, and inoculum's culture age on growth and sesquiterpene production in Artemisia annua L. hairy root cultures in vitro. Cell Dev. Biol.-Plant. 33: 306-312.

Wong H.F, Brown G.D. (2002) Dimeric guaianolides and a fulvenoguaianolide from Artemisia myriantha. J. Nat. Prod. 65(4): 481-486.

Xie D., Wang L., Ye H., Li G. (2000) Isolation and production of artemisinin and stigmasterol in hairy root cultures of 
Artemisia annua. Plant Cell Tissue Organ Cult. 63: 161166.

Xie D., Zou Z., Ye H., Li G., Zou Z. (2001) Selection of hairy roots clones of Artemisia annua L. for artemisinin production. Isr. J. Plant Sci. 49 (2): 129-134.

Zeng L., Chen M., Lan X., Liao Z. (2012) Metabolic regulation of the artemisinin biosynthetic pathway in Artemisia annua L. J. Med. Plants Res. 6(1): 7-13.

Zhangabylov N.S., Dederer L.Y., Gorbacheva L.B., Vasileva S.V., Adekenov S.M. (2004) Sesquiterpene lactone argla- bin influences DNA synthesis in P388 leukemia cells in vivo. Pharm. Chem. J. 38: 651-653.

ZhaoY., Liu Ch. (2007) Biological Production of Artemisinin for Malaria Therapy. In: Medicinal plant biotechnology. From basic research to industrial application, eds. Kayser O., Quax W., Vol. 2. Wiley-VCH Verlag GmbH \& Co. KGaA, Weinheim: 529-542.

Zia M., Mannan A., Chaudhary M.F. (2007) Effect of growth regulators and amino acids on artemisinin production in the callus of Artemisia absinthium. Pak. J. Bot. 39: 799-805. 